\title{
Influence of age and sex steroids on bone density and geometry in middle-aged and elderly European men
}

\author{
K. A. Ward • S. R. Pye • J. E. Adams • S. Boonen • \\ D. Vanderschueren $\cdot$ H. Borghs $\cdot$ J. Gaytant $\cdot$ \\ E. Gielen - G. Bartfai • F. F. Casanueva • J. D. Finn • \\ G. Forti • A. Giwercman • T. S. Han • I. T. Huhtaniemi • \\ K. Kula • F. Labrie • M. E. J. Lean • N. Pendleton • \\ M. Punab • A. J. Silman • F. C. W. Wu • T. W. O'Neill • \\ The EMAS study group
}

Received: 10 February 2010 / Accepted: 27 July 2010 /Published online: 30 October 2010

(C) The Author(s) 2010. This article is published with open access at Springerlink.com

\begin{abstract}
Summary The influence of age and sex steroids on bone density and geometry of the radius was examined in two European Caucasian populations. Age-related change in bone density and geometry was observed. In older men,
\end{abstract}

The EMAS Study Group: Florence (Gianni Forti, Luisa Petrone, Giovanni Corona); Leuven (Dirk Vanderschueren, Steven Boonen, Herman Borghs); Lodz (Krzysztof Kula, Jolanta SlowikowskaHilczer, Renata Walczak-Jedrzejowska); London (Ilpo Huhtaniemi); Malmö (Aleksander Giwercman); Manchester (Frederick Wu, Alan Silman, Terence O’Neill, Joseph Finn, Philip Steer, Abdelouahid Tajar, David Lee, Stephen Pye); Santiago (Felipe Casanueva, Mary Lage); Szeged (Gyorgy Bartfai, Imre Földesi, Imre Fejes); Tartu (Margus Punab, Paul Korrovitz); Turku (Min Jiang)

\section{K. A. Ward ( $\triangle)$}

Nutrition and Bone Health, MRC Human Nutrition Research,

Fulbourn Road,

Cambridge CB1 9NL, UK

e-mail: kate.ward@mrc-hnr.cam.ac.uk

\section{K. A. Ward}

Clinical Radiology, Imaging Science and Biomedical Engineering, Manchester Academic Health Science Centre,

The University of Manchester,

Manchester, UK

S. R. Pye · T. W. O’Neill

Arthritis Research UK Epidemiology Unit, The University of Manchester, Manchester Academic Health Science Centre,

Manchester, UK

J. E. Adams

Clinical Radiology, Imaging Science and Biomedical Engineering,

The University of Manchester, and the Royal Infirmary,

Manchester Academic Health Science Centre,

Manchester, UK bioavailable oestradiol may play a role in the maintenance of cortical and trabecular bone mineral density (BMD).

Introduction To examine the effect of age and sex steroids on bone density and geometry of the radius in two European Caucasian populations.

\section{S. Boonen $\cdot$ E. Gielen}

Leuven University Division of Geriatric Medicine,

Katholieke Universiteit Leuven,

Leuven, Belgium

S. Boonen · D. Vanderschueren · H. Borghs $\cdot$ E. Gielen Leuven University Center for Metabolic Bone Diseases, Katholieke Universiteit Leuven,

Leuven, Belgium

D. Vanderschueren · J. Gaytant

Department of Andrology and Endocrinology,

Katholieke Universiteit Leuven,

Leuven, Belgium

G. Bartfai

Department of Obstetrics, Gynaecology and Andrology, Albert Szent-Gyorgy Medical University,

Szeged, Hungary 
Methods European Caucasian men aged 40-79 years were recruited from population registers in two centres: Manchester (UK) and Leuven (Belgium), for participation in the European Male Ageing Study. Total testosterone (T) and oestradiol $\left(\mathrm{E}_{2}\right)$ were measured by mass spectrometry and the free and bioavailable fractions calculated. Peripheral quantitative computed tomography was used to scan the radius at distal $(4 \%)$ and midshaft $(50 \%)$ sites.

Results Three hundred thirty-nine men from Manchester and 389 from Leuven, mean ages 60.2 and 60.0 years, respectively, participated. At the $50 \%$ radius site, there was a significant decrease with age in cortical BMD, bone mineral content (BMC), cortical thickness, and muscle area, whilst medullary area increased. At the $4 \%$ radius site, trabecular and total volumetric BMD declined with age. Increasing bioavailable $\mathrm{E}_{2}\left(\mathrm{bioE}_{2}\right)$ was associated with increased cortical BMD (50\% radius site) and trabecular BMD (4\% radius site) in Leuven, but not Manchester, men. This effect was predominantly in those aged 60 years and over. In older Leuven men, bioavailable testosterone (Bio T) was linked with increased cortical BMC, muscle area and SSI $(50 \%$ radius site) and total area ( $4 \%$ radius site).

Conclusions There is age-related change in bone density and geometry at the midshaft radius in middle-aged and elderly European men. In older men bio $\mathrm{E}_{2}$ may maintain cortical and trabecular BMD. BioT may influence bone health through associations with muscle mass and bone area.

\section{F. F. Casanueva}

Department of Medicine, Santiago de Compostela University, Complejo Hospitalario Universitario de Santiago (CHUS); CIBER de Fisiopatología Obesidad y Nutricion (CB06/03), Instituto Salud Carlos III,

Santiago de Compostela, Spain

\section{J. D. Finn • F. C. W. Wu}

Andrology Research Unit, Developmental and Regenerative Biomedicine Research Group, The University of Manchester, Manchester Academic Health Science Centre,

Manchester Royal Infirmary,

Manchester, UK

\section{G. Forti}

Endocrinology Unit, Department of Clinical Physiopathology, University of Florence,

Florence, Italy

\section{A. Giwercman}

Reproductive Medicine Centre, Skåne University Hospital, University of Lund,

Malmo, Sweden

\section{T. S. Han}

Department of Endocrinology, University College London, London, UK
Keywords Ageing · Epidemiology · Osteoporosis . Peripheral quantitative computed tomography $\cdot$ Sex hormones

\section{Introduction}

Osteoporosis in men is an increasing but under-appreciated clinical and public health problem with the lifetime risk of fracture in men at age 50 years estimated at $21 \%$ [1]. As in women, increasing age is one of the major determinants of osteoporosis and fracture risk in men. Most studies examining changes in bone health with age have focused on "areal" bone mineral density $\left(\mathrm{g} / \mathrm{cm}^{2}\right.$; $\mathrm{BMD}_{\mathrm{a}}$ ) [2] as measured by dual-energy X-ray absorptiometry (DXA) [3-6]. There are limitations, however, in assessment of bone health using DXA. In particular, DXA tends to overestimate BMD in larger, and underestimate in smaller, bones. Furthermore, bone strength and susceptibility to fracture is influenced not only by the bone mineral content (BMC) but also bone shape and mineral distribution and the loading conditions to which the bone is subjected. Peripheral quantitative computed tomography (pQCT) allows assessment of both bone geometry and material properties including volumetric density (BMD). In contrast to age-related changes in DXA $\mathrm{BMD}_{\mathrm{a}}$ in men there are relatively few data concerning

\section{T. Huhtaniemi}

Department of Reproductive Biology, Imperial College London,

Hammersmith Campus,

London, UK

\section{K. Kula}

Department of Andrology and Reproductive Endocrinology,

Medical University of Lodz,

Lodz, Poland

\section{F. Labrie}

Laboratory of Molecular Endocrinology and Oncology,

Laval University,

Quebec City, QC, Canada

M. E. J. Lean

Department of Human Nutrition, University of Glasgow, Glasgow, Scotland, UK

N. Pendleton

School of Community Based Medicine,

The University of Manchester, Salford Royal NHS Trust, Salford, UK

M. Punab

Andrology Unit, United Laboratories of Tartu University Clinics, Tartu, Estonia

A. J. Silman

Arthritis Research UK,

Chesterfield, UK 
change in BMD as assessed by pQCT and bone structure with age.

Levels of sex steroids are known to be associated with $\mathrm{BMD}_{\mathrm{a}}$, as assessed using DXA, and also rate of bone loss [7-13]. The contribution of oestradiol $\left(\mathrm{E}_{2}\right)$ to BMD has been reasonably well established but the effect of testosterone $(\mathrm{T})$ is less clear, as are the effects of sex hormones on bone structural parameters. Khosla et al. [9, 14] showed that oestradiol $\left(\mathrm{E}_{2}\right)$ was the most constant predictor of BMD and geometry, measured by QCT, with the effect being more marked in elderly men as age-related declines in sex steroids become relevant. Similarly in the MINOS cohort, $\mathrm{E}_{2}$ was related to DXA $\mathrm{BMD}_{\mathrm{a}}$ cortical thickness and area [15]. There is some evidence to suggest a threshold effect of oestrogen, particularly in cortical bone, below which the male skeleton may suffer oestrogen-related bone loss similar to that in the post menopausal female - the threshold level being the median value of bioavailable (bio) $\mathrm{E}_{2}(<30 \mathrm{pM})$ in older $(>60$ years $)$ men $[8,14]$. Testosterone (T) has been linked with cortical and trabecular BMD [14, 16] with conflicting data on effects on bone geometry. Some studies have observed an association between testosterone and bone loss in males [13] whilst others have shown little or no effect, be it assessing $\mathrm{BMD}_{\mathrm{a}}$ or increased fracture risk $[15,17-19]$; geometric parameters were not reported in these studies.

The aims of this cross-sectional study were: firstly to determine the influence of age on BMD and bone structure at the radius in middle-aged and elderly European men; secondly to determine the relationship between BMD and bone structure with sex steroid levels, and thirdly to determine whether the strength of any association between bioE $_{2}$ and BMD differ above and below a threshold level of $\mathrm{bioE}_{2}$ defined as the median value among older men (60 years and over).

\section{Materials and methods}

\section{Subjects}

The subjects included in this analysis were recruited for participation in the European Male Ageing Study (EMAS), a prospective study of ageing in European Caucasian community-dwelling men. Detailed methods have been described previously [20]. Briefly, men were recruited from population-based sampling frames in eight centres between 2003 and 2005. Stratified random sampling was used with the aim of recruiting equal numbers of men in each of four 10-year age bands: 40 49 years, 50-59 years, 60-69 years, and 70-79 years. Letters of invitation were sent to subjects asking them to attend for health assessments by a range of health questionnaires, physical and cognitive performance tests, anthropometry and a fasting blood sample. In two centres, Manchester (UK) and Leuven (Belgium) subjects had pQCT measurements performed at the radius. Ethics approval for the study was obtained in accordance with local institutional requirements in each centre, and each participant gave written informed consent.

\section{Peripheral quantitative computed tomography}

Peripheral QCT measurements of the non-dominant radius were made in men recruited to the Manchester and Leuven centres using XCT-2000 scanners (Stratec, Pforzheim, Germany). At the distal (4\%) site total and trabecular BMD $\left(\mathrm{mg} / \mathrm{cm}^{3}\right)$ and bone cross-sectional area $\left(\mathrm{mm}^{2}\right)$ were measured (voxel size, $0.4 \mathrm{~mm}$ ); the slice location at the $4 \%$ and $50 \%$ site was more distal in Leuven compared with Manchester; the reference line was placed at the distal border of the radial endplate in Leuven, in Manchester the line is placed to bisect the lateral border of the endplate these differences result in a scan site difference approximately 1-2 $\mathrm{mm}$ between centers. At the diaphysis $(50 \%$ site, voxel size $0.6 \mathrm{~mm})$, cortical BMD $\left(\mathrm{mg} / \mathrm{cm}^{3}\right)$, cortical BMC (mg/mm), total, cortical and medullary areas $\left(\mathrm{mm}^{2}\right)$, cortical thickness $(\mathrm{mm})$, stress strain index (SSI, $\mathrm{mm}^{3}$ ) and muscle cross-sectional area, as a proxy for muscle strength (CSMA, $\mathrm{mm}^{2}$ ), were measured. SSI provides a measure of a bone's torsional strength [21, 22].

Table 1 Subject characteristics: by centre

\begin{tabular}{lcc}
\hline Variable & $\begin{array}{l}\text { Manchester } \\
N=339 \\
\text { Mean }(\mathrm{SD})\end{array}$ & $\begin{array}{l}\text { Leuven } \\
N=389 \\
\text { Mean (SD) }\end{array}$ \\
\hline Age at interview (years) & $60.2(11.1)$ & $60.0(11.1)$ \\
Height $(\mathrm{cm})$ & $174.3(7.2)$ & $174.5(7.1)$ \\
Weight $(\mathrm{kg})$ & $83.8(13.4)$ & $82.1(13.2)$ \\
Body mass index $\left(\mathrm{kg} / \mathrm{m}^{2}\right)$ & $27.5(3.6)$ & $26.9(3.9)^{*}$ \\
Midshaft radius & & \\
Cortical BMD $\left(\mathrm{mg} / \mathrm{cm}^{3}\right)$ & $1,149.8(39.8)$ & $1,161.0(38.0)^{*}$ \\
Cortical BMC $\left(\mathrm{mg} / \mathrm{mm}^{2}\right)$ & $120.5(18.0)$ & $124.0(17.2)^{*}$ \\
Total area $\left(\mathrm{mm}{ }^{2}\right)$ & $149.5(21.5)$ & $150.5(22.3)$ \\
Cortical thickness $\left(\mathrm{mm}^{2}\right)$ & $3.2(0.5)$ & $3.2(0.4)$ \\
Medullary area $\left.(\mathrm{mm})^{2}\right)$ & $43.4(17.2)$ & $43.7(18.9)$ \\
Cross-sectional muscle $\mathrm{area}_{\left(\mathrm{mm}^{2}\right)} 3,558.3(649.3)$ & $3,744.8(591.6)^{*}$ \\
Stress strain index $\left(\mathrm{mm}^{3}\right)$ & $330.3(63.4)$ & $345.6(67.1)^{*}$ \\
Distal radius & & \\
Total density $\left(\mathrm{mg} / \mathrm{cm}^{3}\right)$ & $436.3(70.1)$ & $361.1(57.3)^{*}$ \\
Total area $\left(\mathrm{mm}{ }^{2}\right)$ & $341.2(52.5)$ & $413.1(66.7)^{*}$ \\
Trabecular density $\left(\mathrm{mg} / \mathrm{cm}^{3}\right)$ & $203.9(48.0)$ & $205.5(41.4)$ \\
\hline
\end{tabular}

$* p<0.05$ 
Table 2 Sex hormone descriptives: by centre

\begin{tabular}{lcc}
\hline Variable & $\begin{array}{l}\text { Manchester } \\
N=339 \\
\text { Mean }(\mathrm{SD})\end{array}$ & $\begin{array}{l}\text { Leuven } \\
N=389 \\
\text { Mean }(\mathrm{SD})\end{array}$ \\
\hline Testosterone (nmol/L) & $17.3(6.2)$ & $18.6(5.9)^{*}$ \\
Free testosterone (pmol/L) & $306.1(91.1)$ & $324.8(88.6)^{*}$ \\
Bioavailable testosterone (nmol/L) & $7.6(2.3)$ & $8.2(2.3)^{*}$ \\
Oestradiol $(\mathrm{pmol} / \mathrm{L})$ & $80.4(25.7)$ & $73.5(24.2)^{*}$ \\
Free oestradiol $(\mathrm{pmol} / \mathrm{L})$ & $1.4(0.4)$ & $1.2(0.4)^{*}$ \\
Bioavailable oestradiol $(\mathrm{pmol} / \mathrm{L})$ & $56.4(18.0)$ & $51.2(17.0)^{*}$ \\
SHBG (nmol/L) & $42.0(18.2)$ & $43.7(19.2)$
\end{tabular}

Reference range in healthy men aged 18-29 years for total testosterone measured by mass spectroscopy (MS) is $9-42 \mathrm{nmol} / \mathrm{L}$ and for calculated free testosterone $146-555 \mathrm{pmol} / \mathrm{L}$ [36]. There are at present no published reference ranges for oestradiol measured by MS in healthy young men. Reference range in healthy men aged 20 years for SHBG measured by immunoassay is $13-53 \mathrm{nmol} / \mathrm{L}$ [37]

$* p<0.05$

A detailed methodology for these measurements has been described previously [23].

For cross-calibration between Leuven and Manchester the European Forearm Phantom (EFP) was measured [24]; 10 repeat measurements were taken in slices $1-4$. There were no differences greater than precision error for trabecular, total and cortical BMD, BMC or cortical area. Therefore no cross-calibration was performed between the two centres. These data and decisions were reviewed by Dr Klaus Engelke a CT expert from University of
Erlangen, Germany and the scanner manufacturer Stratec Medizintechnik GmbH, Profzheim, Germany (Dr. Johannes Willnecker-personal communication).

The short term precision of two repeat radius measurements with repositioning in adults were: Manchester $(n=22)$ Leuven $(n=40)$ trabecular BMD $1.27 \%, 1.42 \%$; total BMD $2.1 \%, 1.3 \%$; cortical BMD $0.77 \%, 0.71 \%$; cortical area $2.4 \%, 1.3 \%$; muscle area $3.7 \%, 1.1 \%$. Manufacturer's standard quality assurance procedures were followed in both centres.

Sex hormone measurement

A single-fasting morning (before $10.00 \mathrm{~h}$ ) venous blood sample was obtained from all subjects. Serum was separated immediately after phlebotomy and stored at $-80^{\circ} \mathrm{C}$ until assay at the end of the baseline study. Measurement of $\mathrm{T}$ and $\mathrm{E}_{2}$ were carried out by gas chromatography mass spectrometry as described in Labrie et al. [25, 26]. The lower limit of $\mathrm{T}$ quantitation was $0.17 \mathrm{nmol} / \mathrm{L}$ and $\mathrm{E}_{2}$ was $7.34 \mathrm{pmol} / \mathrm{L}$. The coefficients of variation of $\mathrm{T}$ measurements were $2.9 \%$ within runs and $3.4 \%$ between runs, and for $\mathrm{E}_{2}$, were $3.5 \%$ within runs and $3.7 \%$ between runs. SHBG was measured by the Modular E170 platform electrochemiluminescence immunoassay (Roche Diagnostics, Mannheim, Germany) as previously described [27]. Free and bioT and $\mathrm{E}_{2}$ levels were derived from total $\mathrm{T}$, total $\mathrm{E}_{2}, \mathrm{SHBG}$, and albumin concentrations using mass action equations and associations constants of Van Pottelbergh et al. and Vermeulen et al. [12, 28].

Table 3 Influence of age on pQCT parameters at the radius: by centre

\begin{tabular}{|c|c|c|c|c|}
\hline & \multicolumn{2}{|l|}{ Manchester } & \multicolumn{2}{|l|}{ Leuven } \\
\hline & $\beta$ co-efficient $^{\mathrm{a}}(95 \% \mathrm{CI})$ & $\%$ change/year & $\beta$ co-efficient $^{\mathrm{a}}(95 \% \mathrm{CI})$ & $\%$ change/year \\
\hline \multicolumn{5}{|l|}{ Midshaft radius } \\
\hline Cortical BMD & $-1.210(-1.573,-0.846)^{*}$ & -0.107 & $-0.894(-1.225,-0.562)^{*}$ & -0.077 \\
\hline Cortical BMC & $-0.290(-0.462,-0.119)^{*}$ & -0.271 & $-0.260(-0.414,-0.108)^{*}$ & -0.208 \\
\hline Total area & $0.176(-0.032,0.384)$ & 0.119 & $0.060(-0.142,0.261)$ & 0.040 \\
\hline Cortical thickness & $-0.010(-0.014,-0.005)^{*}$ & -0.319 & $-0.007(-0.010,-0.003)^{*}$ & -0.219 \\
\hline Medullary area & $0.310(0.147,0.473)^{*}$ & 0.824 & $0.206(0.036,0.375)^{*}$ & 0.471 \\
\hline Stress strain index & $-0.022(-0.637,0.593)$ & -0.021 & $-0.510(-1.114,0.094)$ & -0.148 \\
\hline $\mathrm{CSMA}^{\mathrm{b}}$ & $-20.561(-26.464,-14.658)^{*}$ & -0.567 & $-14.763(-19.908,-9.618)^{*}$ & -0.394 \\
\hline \multicolumn{5}{|l|}{ Distal radius } \\
\hline Total density & $-1.847(-2.498,-1.196)^{*}$ & -0.446 & $-1.665(-2.157,-1.172)^{*}$ & -0.461 \\
\hline Total area & $0.413(-0.094,0.921)$ & 0.114 & $0.501(-0.102,1.103)$ & 0.121 \\
\hline Trabecular density & $-0.676(-1.137,-0.216)^{*}$ & -0.397 & $-0.452(-0.825,-0.079)^{*}$ & -0.220 \\
\hline
\end{tabular}

$* p<0.05$

${ }^{a}$ Change in each pQCT parameter per 1 year increase in age

${ }^{\mathrm{b}}$ Cross-sectional muscle area 
Statistical analysis

Linear regression was used to explore the association between age and various pQCT parameters as dependent variables; and the results expressed as unstandardised $\beta$ coefficients and 95\% confidence intervals. Regression analysis was also used to investigate the association between pQCT parameters and sex hormones (analysed as continuous variables) including total, free and bioavailable $\mathrm{E}_{2}$ and T. Adjustments were made in these analyses for age,
Fig. 1 a Association between cortical BMD at the midshaft radius and age: by centre. $\mathbf{b}$ Association between stress strain index at the midshaft radius and age: by centre. $\mathbf{c}$ Association between cross-sectional muscle area at the midshaft radius and age: by centre. d Association between total density at the distal radius and age: by centre a

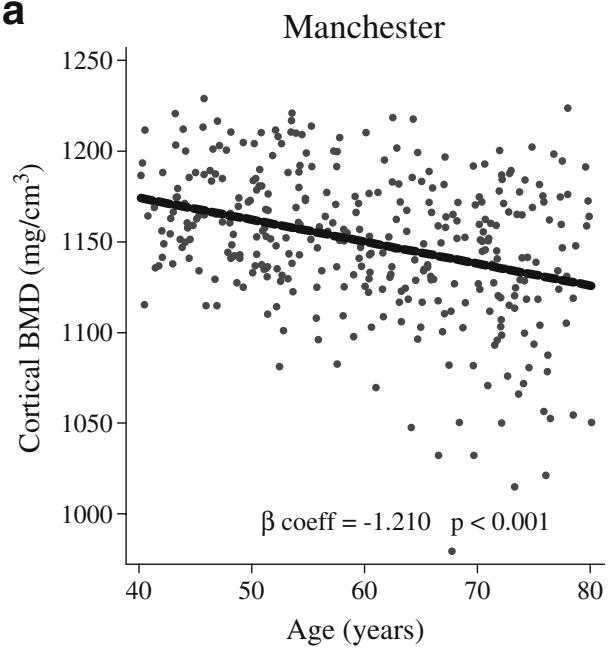

b

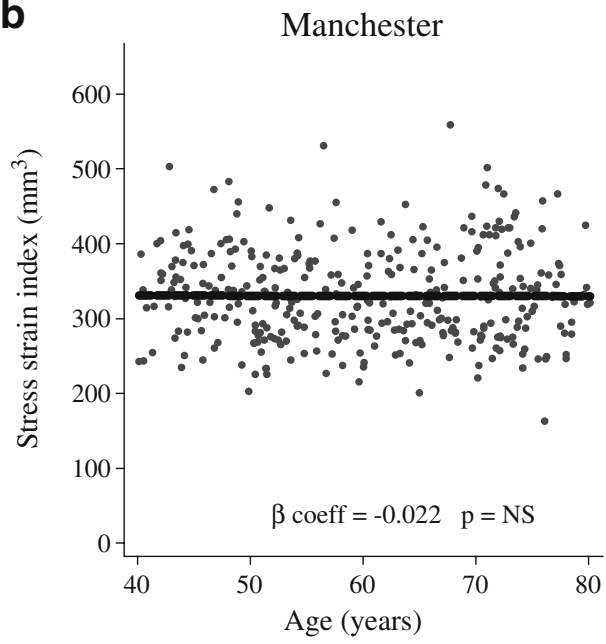

C

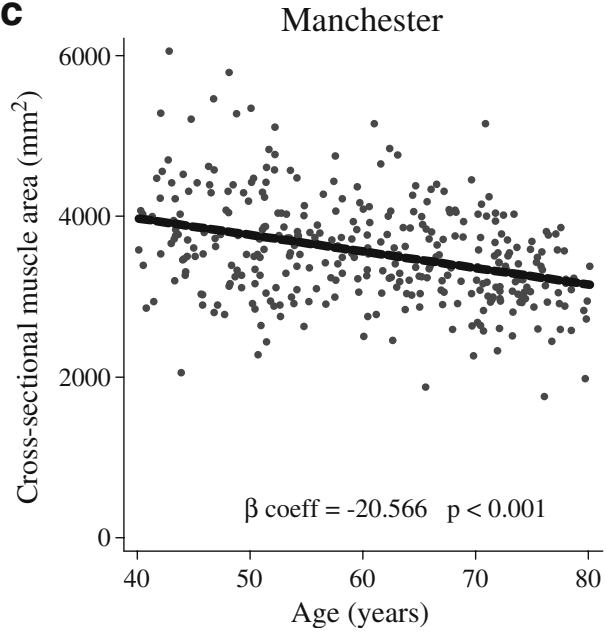

Leuven

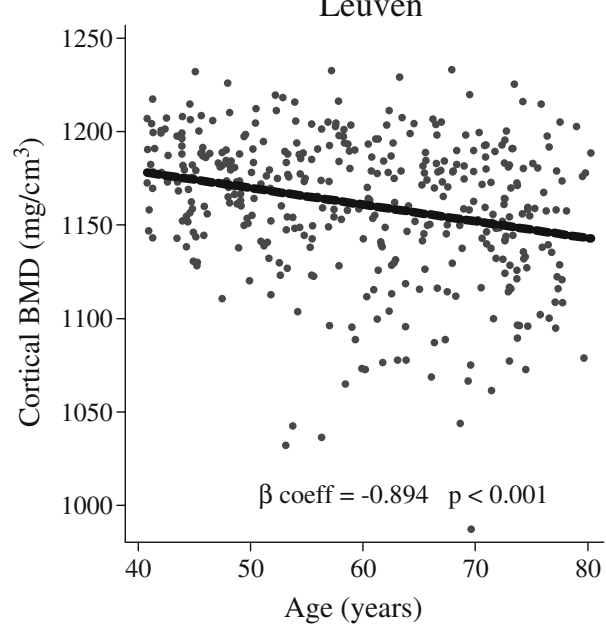

Leuven

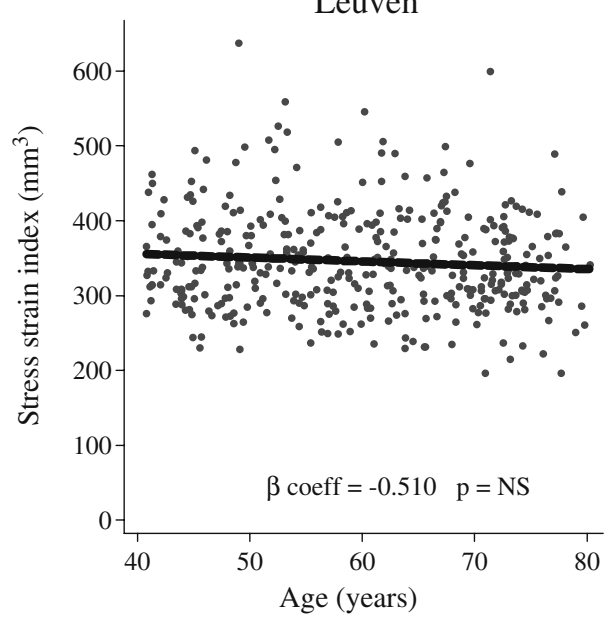

Leuven

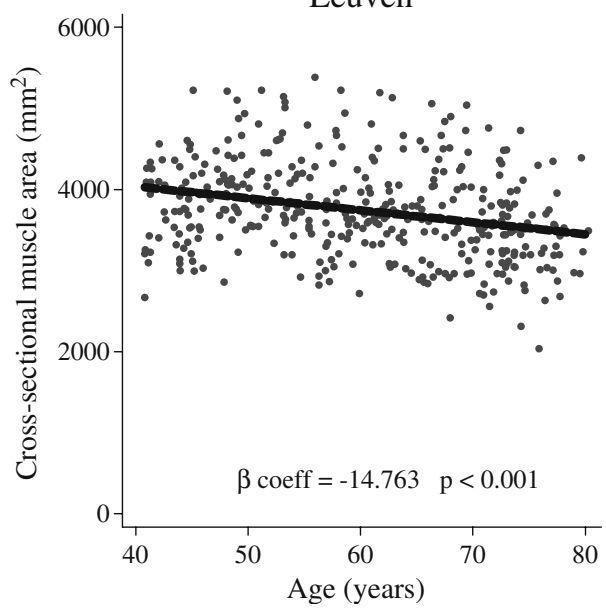


Fig. 1 (continued)
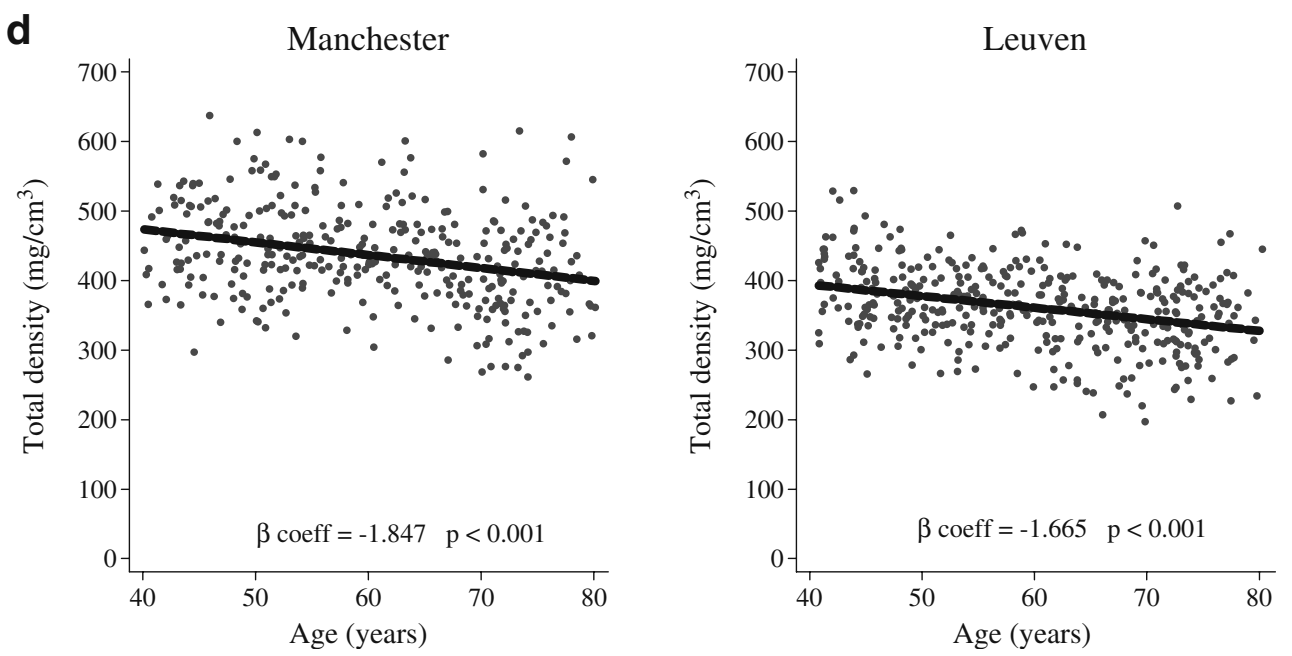

height and weight as these variables were found to have significant independent associations with the pQCT parameters. We tested for a centre interaction for the hormone and pQCT regressions. For some parameters, there was a significant interaction and therefore our analyses were performed in each centre separately. Based on previous data suggesting an influence of age on the association between sex hormone status and pQCT parameters, the analysis was repeated after stratification by age $(<60$ and $>60$ years) [14]. Subjects were categorised into those above or below a bio: $\mathrm{E}_{2}$ threshold, defined as the median value in those over 60 years $(51 \mathrm{pmol} / \mathrm{L})$ and the association between bioE $\mathrm{E}_{2}$ and BMD measurements (at both $4 \%$ and $50 \%$ sites) examined. All data from the two centres were analysed separately. Statistical analysis was performed using STATA version 9.2 (http://www.stata.com).

\section{Results}

\section{Subject characteristics}

Three hundred thirty-nine men from Manchester and 389 from Leuven participated in this study. Their mean ages were 60.2 and 60.0 years, respectively. There were no differences in height or weight between subjects recruited in the two centres, but body mass index was slightly greater in Manchester (27.5 vs $26.9 \mathrm{~kg} / \mathrm{m}^{2}$ ), see Table 1. Cortical BMD and BMC at the midshaft, and also cross-sectional muscle area and SSI were significantly greater in subjects recruited in Leuven, Table 1. At the distal radial (4\%) site, radial area was greater in Leuven and total BMD lower in Leuven compared to Manchester, indicating the slightly different scan location (in more distal thus expanded radius site in Leuven).

Sex hormone levels in the different centres are presented in Table 2. The mean serum $\mathrm{T}$ levels (total, free and bioavailable) were higher in Leuven than Manchester while the total, free and bioavailable $\mathrm{E}_{2}$ levels were lower. There was no difference in SHBG levels in the two centres.

Age-related variations in bone mass and geometry

At the 50\% midshaft site, lower cortical BMD, BMC, thickness and muscle area, and greater medullary area were decreased with age. There were no age-related variations in bone strength as assessed by SSI, (Table 3, Fig. 1) at either study centre. There were small though nonsignificant increases in bone area with age. For all parameters the change with age was broadly linear across the age range with no evidence of accelerated loss in later life. At the distal radius, there was a negative association of both trabecular and total BMD with age in both centres, Fig. 1.

\section{Influence of sex hormones on $\mathrm{pQCT}$ parameters}

The association between total, free, and bioavailable fractions of $\mathrm{T}$ and $\mathrm{E}_{2}$ with $\mathrm{pQCT}$ parameters were broadly similar. We present data here for the bioavailable hormone relationships $\left(\mathrm{bioE}_{2}\right.$, bioavailable testosterone (bioT)) (Table 4). In Leuven men, higher bioE $_{2}$ was associated with increased cortical BMD at the 50\% site and trabecular BMD at the $4 \%$ site; higher bioE $_{2}$ was associated also with greater cortical thickness and smaller medullary area. There was no important effect of bioT on BMD at either site. BioT was positively associated with CSMA in the Leuven men. There were no significant associations with any of the skeletal parameters in the Manchester men other than a negative association between total area (4\% site) and bioE $_{2}$. Based on previous data [14] suggesting an influence of age on the association between sex hormone status and pQCT parameters, we analysed men above and below 60 years separately. The data are presented in Table 5. In Leuven men, all the significant 
Table 4 Influence of bioavailable testosterone and oestradiol on pQCT parameters at the radius: by centre

$\begin{array}{ll}\text { Manchester } & \text { Leuven } \\ \beta \text { co-efficient }^{\mathrm{a}}(95 \% \mathrm{CI}) & \beta \text { co-efficient }{ }^{\mathrm{a}}(95 \% \mathrm{CI})\end{array}$

\begin{tabular}{|c|c|c|}
\hline \multicolumn{3}{|c|}{ Midshaft radius } \\
\hline \multicolumn{3}{|c|}{ Cortical BMD } \\
\hline BioT & $-0.427(-2.505,1.651)$ & $0.583(-1.354,2.519)$ \\
\hline $\mathrm{BioE}_{2}$ & $-0.006(-0.237,0.225)$ & $0.393(0.167,0.618)^{*}$ \\
\hline \multicolumn{3}{|c|}{ Cortical BMC } \\
\hline BioT & $0.235(-0.676,1.145)$ & $0.812(-0.009,1.633)$ \\
\hline $\mathrm{BioE}_{2}$ & $-0.056(-0.157,0.046)$ & $0.094(-0.002,0.190)$ \\
\hline \multicolumn{3}{|c|}{ Total area } \\
\hline BioT & $0.140(-0.934,1.214)$ & $0.511(-0.590,1.612)$ \\
\hline $\mathrm{BioE}_{2}$ & $-0.072(-0.191,0.047)$ & $-0.107(-0.236,0.022)$ \\
\hline \multicolumn{3}{|c|}{ Cortical thickness } \\
\hline BioT & $-0.002(-0.026,0.023)$ & $0.018(-0.004,0.040)$ \\
\hline $\mathrm{BioE}_{2}$ & $-0.001(-0.004,0.002)$ & $0.004(0.001,0.006)^{*}$ \\
\hline \multicolumn{3}{|c|}{ Medullary area } \\
\hline BioT & $0.028(-0.840,0.896)$ & $-0.160(-1.145,0.825)$ \\
\hline $\mathrm{BioE}_{2}$ & $-0.030(-0.127,0.066)$ & $-0.156(-0.272,-0.040)^{*}$ \\
\hline \multicolumn{3}{|c|}{ Stress strain index } \\
\hline BioT & $1.090(-2.139,4.319)$ & $2.541(-0.730,5.812)$ \\
\hline $\mathrm{BioE}_{2}$ & $-0.184(-0.543,0.175)$ & $-0.106(-0.485,0.274)$ \\
\hline \multicolumn{3}{|l|}{$\mathrm{CSMA}^{\mathrm{b}}$} \\
\hline BioT & $4.020(-25.383,33.424)$ & $31.382(7.565,55.198)^{*}$ \\
\hline $\mathrm{BioE}_{2}$ & $-2.073(-5.334,1.188)$ & $1.099(-1.733,3.931)$ \\
\hline \multicolumn{3}{|c|}{ Distal radius } \\
\hline \multicolumn{3}{|c|}{ Total density } \\
\hline BioT & $0.288(-3.397,3.974)$ & $-0.472(-3.261,2.317)$ \\
\hline $\mathrm{BioE}_{2}$ & $0.248(-0.161,0.656)$ & $0.259(-0.069,0.586)$ \\
\hline \multicolumn{3}{|c|}{ Total area } \\
\hline BioT & $-0.295(-2.994,2.403)$ & $3.241(-0.107,6.590)$ \\
\hline $\mathrm{BioE}_{2}$ & $-0.313(-0.611,-0.015)^{*}$ & $0.134(-0.263,0.531)$ \\
\hline \multicolumn{3}{|c|}{ Trabecular density } \\
\hline BioT & $0.590(-2.043,3.224)$ & $0.399(-1.742,2.540)$ \\
\hline $\mathrm{BioE}_{2}$ & $0.087(-0.206,0.379)$ & $0.316(0.064,0.568)^{*}$ \\
\hline
\end{tabular}

${ }^{*} p<0.05$

${ }^{a}$ Adjusted for age, height, and weight

${ }^{\mathrm{b}}$ Cross-sectional muscle area

associations observed in the unstratified analysis were observed exclusively in the older men. Furthermore, among Leuven men older than 60 years, a number of significant associations emerged that were not present in the unstratified analysis. There was a positive association between bioE $_{2}$ and cortical $\mathrm{BMC}$ at the $50 \%$ site and total BMD at the $4 \%$ site. There were positive associations also between bioT and (1) cortical BMC and stress strain index at the $50 \%$ site and (2) total area at the $4 \%$ site.
Influence of threshold level of bioavailable oestradiol

The median bioE $_{2}$ in men (both centres combined) over 60 years was $51 \mathrm{pmol} / \mathrm{L}$. Among the Leuven men, after adjusting for age, height, and weight there was a significant association between bioE $\mathrm{E}_{2}$ and cortical BMD at the $50 \%$ site among those above and below this threshold. The magnitude of effect associated with trabecular BMD at the $4 \%$ site was broadly similar among those above and below the threshold, but because of smaller numbers neither association was statistically significant, see Table 6 . There was no association between bioE $_{2}$ and $\mathrm{BMD}$ in either compartment in Manchester men.

\section{Discussion}

Our data confirm evidence of age-related change at the midshaft radius in cortical BMD and BMC, cortical thickness and medullary area in middle-aged and elderly men. Among older Leuven men oestrogen appeared to play a role in maintaining BMD. BioT had no effect on BMD, but may influence bone health through an effect on muscle mass and bone area.

Our data confirm that there is lower BMC, thinner cortex and larger medullary area at the radial diaphysis, and also a lower muscle area in ageing men. Despite the lower BMC and muscle area with ageing it is possible bone strength is maintained through periosteal apposition (indicated by marginally greater bone area in older men). These data are consistent with those previously reported at the distal site, with loss of trabecular and total BMD [29] and a gain of bone on the periosteal surface. The periosteal apposition at this site has been shown to maintain strength and may be one reason why the incidence of forearm fracture is lower in men (than women) [30]. Taking muscle area as a surrogate for loading, it is plausible that the small adaptations in bone geometry can maintain strength to the level required for reduced loading from muscles.

Evidence from observational and clinical studies support the view that oestrogen is the most important sex steroid in determining bone mass in men [7-12]. Our finding of a positive relationship between $\mathrm{E}_{2}$ and BMD at both the $4 \%$ and $50 \%$ sites in the Leuven men is consistent with this view. The association with bioE $_{2}$ was stronger in the older, than the younger, men which would be consistent with a lower level of bioavailable hormone in older age. Khosla et al. reported evidence of a threshold level of $\operatorname{bioE}_{2}(30 \mathrm{pM})$ above which no association with oestrogen was observed in cortical BMD, but not trabecular, bone at a range of skeletal sites (femoral neck, distal radius, and distal tibia) [14]. The threshold used, defined as the 
Table 5 Influence of bioavailable testosterone and oestradiol on pQCT parameters at the radius: by age and centre

\begin{tabular}{|c|c|c|c|c|}
\hline & \multicolumn{2}{|l|}{ Manchester } & \multicolumn{2}{|l|}{ Leuven } \\
\hline & $\begin{array}{l}\text { Age }<60 \\
\beta \text { co-efficient }{ }^{\mathrm{a}}(95 \% \mathrm{CI})\end{array}$ & $\begin{array}{l}\text { Age } \geq 60 \\
\beta \text { co-efficient }{ }^{\mathrm{a}}(95 \% \mathrm{CI})\end{array}$ & $\begin{array}{l}\text { Age }<60 \\
\beta \text { co-efficient }{ }^{\mathrm{a}}(95 \% \mathrm{CI})\end{array}$ & $\begin{array}{l}\text { Age } \geq 60 \\
\beta \text { co-efficient }{ }^{\mathrm{a}}(95 \% \mathrm{CI})\end{array}$ \\
\hline \multicolumn{5}{|c|}{ Midshaft radius } \\
\hline \multicolumn{5}{|c|}{ Cortical BMD } \\
\hline BioT & $-1.282(-3.559,0.994)$ & $0.336(-3.232,3.905)$ & $-1.631(-4.039,0.778)$ & $3.117(-0.072,6.305)$ \\
\hline $\mathrm{BioE}_{2}$ & $-0.046(-0.319,0.228)$ & $0.030(-0.337,0.397)$ & $0.107(-0.182,0.396)$ & $0.699(0.348,1.050)^{*}$ \\
\hline \multicolumn{5}{|c|}{ Cortical BMC } \\
\hline BioT & $-0.116(-1.233,1.001)$ & $0.513(-0.943,1.970)$ & $0.031(-1.104,1.166)$ & $1.818(0.576,3.059)^{*}$ \\
\hline $\mathrm{BioE}_{2}$ & $-0.146(-0.278,-0.014)^{*}$ & $0.013(-0.137,0.163)$ & $0.006(-0.126,0.137)$ & $0.198(0.057,0.340)^{*}$ \\
\hline \multicolumn{5}{|c|}{ Total area } \\
\hline BioT & $0.635(-0.858,2.127)$ & $-0.341(-1.884,1.201)$ & $0.147(-1.371,1.665)$ & $1.170(-0.508,2.848)$ \\
\hline $\mathrm{BioE}_{2}$ & $-0.085(-0.264,0.093)$ & $-0.052(-0.211,0.106)$ & $-0.075(-0.250,0.100)$ & $-0.127(-0.319,0.064)$ \\
\hline \multicolumn{5}{|c|}{ Cortical thickness } \\
\hline BioT & $-0.014(-0.045,0.017)$ & $0.008(-0.029,0.044)$ & $0.005(-0.024,0.034)$ & $0.035(-0.002,0.071)$ \\
\hline $\mathrm{BioE}_{2}$ & $-0.003(-0.006,0.001)$ & $-0.050(-0.184,0.085)$ & $0.002(-0.002,0.005)$ & $0.006(0.002,0.010)^{*}$ \\
\hline \multicolumn{5}{|c|}{ Medullary area } \\
\hline BioT & $0.578(-0.559,1.715)$ & $-0.437(-1.746,0.872)$ & $-0.044(-1.269,1.181)$ & $-0.153(-1.803,1.496)$ \\
\hline $\mathrm{BioE}_{2}$ & $0.010(-0.127,0.147)$ & $-0.050(-0.184,0.085)$ & $-0.074(-0.220,0.071)$ & $-0.239(-0.424,-0.054)^{*}$ \\
\hline \multicolumn{5}{|c|}{ Stress strain index } \\
\hline BioT & $2.103(-2.304,6.511)$ & $-0.177(-4.914,4.559)$ & $-0.580(-5.335,4.174)$ & $6.186(1.526,10.846)^{*}$ \\
\hline $\mathrm{BioE}_{2}$ & $-0.344(-0.870,0.183)$ & $-0.053(-0.540,0.434)$ & $-0.250(-0.789,0.288)$ & $0.078(-0.461,0.617)$ \\
\hline \multicolumn{5}{|l|}{$\operatorname{CSMA}^{\mathrm{b}}$} \\
\hline BioT & $27.979(-14.973,70.931)$ & $-25.644(-65.546,14.257)$ & $20.499(-14.140,55.137)$ & $49.118(15.313,82.922)^{*}$ \\
\hline $\mathrm{BioE}_{2}$ & $-1.363(-6.531,3.806)$ & $-3.183(-7.279,0.913)$ & $2.933(-1.173,7.040)$ & $-0.489(-4.405,3.427)$ \\
\hline \multicolumn{5}{|c|}{ Distal radius } \\
\hline \multicolumn{5}{|c|}{ Total density } \\
\hline BioT & $-3.349(-8.094,1.396)$ & $3.623(-2.008,9.255)$ & $-1.617(-5.374,2.140)$ & $1.331(-3.019,5.680)$ \\
\hline $\mathrm{BioE}_{2}$ & $0.223(-0.347,0.794)$ & $0.238(-0.343,0.818)$ & $-0.086(-0.533,0.360)$ & $0.639(0.156,1.121)^{*}$ \\
\hline \multicolumn{5}{|c|}{ Total area } \\
\hline BioT & $1.536(-2.117,5.188)$ & $-2.362(-6.361,1.636)$ & $0.772(-3.620,5.165)$ & $6.111(0.783,11.440)^{*}$ \\
\hline $\mathrm{BioE}_{2}$ & $-0.355(-0.790,0.080)$ & $-0.261(-0.672,0.150)$ & $0.354(-0.163,0.871)$ & $-0.106(-0.719,0.508)$ \\
\hline \multicolumn{5}{|c|}{ Trabecular density } \\
\hline BioT & $-1.191(-4.465,2.083)$ & $2.566(-1.640,6.772)$ & $0.588(-2.052,3.228)$ & $0.136(-3.412,3.685)$ \\
\hline $\mathrm{BioE}_{2}$ & $0.104(-0.289,0.497)$ & $0.092(-0.342,0.526)$ & $0.200(-0.115,0.516)$ & $0.420(0.023,0.817)^{*}$ \\
\hline
\end{tabular}

$* p<0.05$

${ }^{a}$ Adjusted for age, height, and weight

${ }^{\mathrm{b}}$ Cross-sectional muscle area

median value in men age 60 years, differed from the value used in our study $(51 \mathrm{pmol} / \mathrm{L})$ which was based on mass spectrometry measurements. Our data do not support these observations of a threshold effect of $\mathrm{bioE}_{2}$ on cortical bone.

The current view is that testosterone acts on bone primarily via aromatisation to estrogens. There is some evidence, at least in rats, that $\mathrm{T}$ may increase periosteal apposition (and thereby increase total area), and certainly in adolescents $\mathrm{T}$ increases periosteal growth. Szulc et al. using data from DXA, suggested an increase in periosteal apposition with age though not via an action of $\mathrm{T}[15$, 31]. In contrast, Khosla et al. found an inverse association in men with higher levels of $\mathrm{T}$ linked with reduced bone area [14]. Our results (both centres) showed no significant change in bone area with increasing testosterone at the $50 \%$ site though there was a positive association at the $4 \%$ site among the older Leuven men.

One of the intriguing findings was the differences in the absolute pQCT parameters between the two centres and the 
Table 6 Influence of bioavailable oestradiol on BMD at the radius in Leuven, Belgium ( $\geq 60$ years): by median bioavailable oestradiol level

Bioavailable oestradiol (pmol/L)

BioE2 $<51 \mathrm{pmol} / \mathrm{L}$

$\beta$ co-efficient $^{\mathrm{a}}(95 \% \mathrm{CI})$

$1.550(0.584,2.516)^{*}$

$0.020(-1.340,1.380)$

$0.410(-0.740,1.561)$
BioE2 $\geq 51 \mathrm{pmol} / \mathrm{L}$

$\beta$ co-efficient ${ }^{\mathrm{a}}(95 \% \mathrm{CI})$

$0.698(0.059,1.338)^{*}$

$0.783(-0.079,1.645)$

$0.516(-0.156,1.187)$
Overall

$\beta$ co-efficient $^{\mathrm{a}}(95 \% \mathrm{CI})$

$0.699(0.348,1.050)^{*}$

$0.639(0.156,1.121)^{*}$

$0.420(0.023,0.817)^{*}$

$* p<0.05$

${ }^{a}$ Adjusted for age, height, and weight

relationships with sex steroids. Subjects in both centres were recruited using the same methods and were from a similar socioeconomic background. Removing subjects $(n=$ 18) who were taking medications known to influence sex steroid levels did not change the results. Further adjustment for smoking and physical activity had no effect on these relationships. The lower total BMD and larger bone area in Leuven at the $4 \%$ site may in part be related to the slightly different and more distal slice location used at the two centres. It is unlikely, however, that this difference in protocol explains centre differences at the $50 \%$ site due to the more homogenous structure of the radius at this anatomical site. It is therefore likely that other explanations, including genetic and environmental factors, play a role in these Manchester-Leuven skeletal and hormone differences. Genetic factors are known to influence both bone mass and structure at the radius. Data from family and twin studies suggest that genetic factors explain about $50 \%$ of the variation in the radius total and trabecular $\mathrm{VBMD}$, and up to $40 \%$ of cortical vBMD [32,33]. In addition, a large proportion of the variation in geometric parameters such as radius cross-sectional area $(27 \%)$ and cortical thickness (51\%) are also attributable to genetic factors [33]. Variations in other skeletal parameters across Europe have previously been reported [34]; however, to the best of our knowledge, there are no data concerning pQCT parameters. We cannot explain the variation in findings in relation to the associations between bone parameters and sex hormones, other than the slight difference in protocol using pQCT which we feel would be unlikely to explain the variation. The similarity in rate of change with age for the skeletal parameters in both centres provides some construct validity to these measures.

The strength of our study was that it was population based and used pQCT measurements to obtain information not only on bone density but also bone morphology. There are some limitations which need to be considered when interpreting the results. The response rate for participation in the study was $45 \%$ [20]. Those who participated may have differed with respect to bone health and/or sex hormone status than those who did not participate. However, the main findings, in relation to the sex steroid levels were based on internal comparisons among responders and so selection factors are unlikely to have had an important effect. One of the key factors in designing the study was to ensure standardisation of the study instruments used in the different participating centres. Hormone measurements were performed in a central reference laboratory to minimise assay variability. The same pQCT scanner type and model was used in each centre and after testing scanner differences with the EFP, no crosscalibration was necessary. There was a small difference in the $4 \%$ and $50 \%$ site location between centres, Leuven being 1-2 $\mathrm{mm}$ more distal in position than Manchester, as evidenced by a larger radial area and a lower total BMD in Leuven compared to Manchester. This emphasizes the need to have very precise and detailed protocols, including an image of the position of the reference line, for performing single-slice $\mathrm{pQCT}$ in multiple centres; quite large differences in the measured parameters can be observed in the $4 \%$ site, even in adjacent slices [35]. Although this may explain differences in BMD and area at the $4 \%$ site between centres, it is unlikely to affect the relationship between these parameters and sex hormones at the $50 \%$ site. Our study was cross-sectional: to determine true age-related changes in bone health prospective data are needed. The results were also obtained from a predominantly Caucasian European population so cannot be extrapolated beyond this setting.

In conclusion, there is evidence of age-related change at the midshaft radius in cortical BMD and BMC, cortical thickness and medullary area in middle-aged and elderly European men. Among older men, $\mathrm{bioE}_{2}$ may play a role in maintaining cortical and trabecular BMD. BioT has no effect on BMD but may influence bone health through an effect on muscle mass and bone area. 
Acknowledgements The European Male Ageing Study (EMAS) is funded by the Commission of the European Communities Fifth Framework Programme "Quality of Life and Management of Living Resources" Grant QLK6-CT-2001-00258 and supported by funding from Arthritis Research UK. For additional information regarding EMAS contact Frederick Wu, MD; Dept of Endocrinology, Manchester Royal Infirmary, UK. The authors wish to thank the men who participated in the eight countries, the research/nursing staff in the eight centres: C Pott, Manchester, E Wouters, Leuven, M Nilsson, Malmö, M del Mar Fernandez, Santiago de Compostela, M Jedrzejowska, Lodz, H-M Tabo, Tartu, A Heredi, Szeged for their data collection and C Moseley, Manchester for data entry and project coordination.

The pQCT measurements were funded through a research grant from Central Manchester Universities Hospitals NHS Foundation Trust Endowment Funds, and the bone densitometry database was prepared for analysis by Mr. Mike Machin.

Dr. Vanderschueren is a senior clinical investigator supported by the Clinical Research Fund of the University Hospitals Leuven, Belgium. Dr. Boonen is a senior clinical investigator of the Fund for Scientific Research-Flanders, Belgium (F.W.O.-Vlaanderen). Dr. Boonen is holder of the Leuven University Chair in Metabolic Bone Diseases.

\section{Conflicts of interest None.}

Open Access This article is distributed under the terms of the Creative Commons Attribution Noncommercial License which permits any noncommercial use, distribution, and reproduction in any medium, provided the original author(s) and source are credited.

\section{References}

1. van Staa TP, Dennison EM, Leufkens HG, Cooper C (2001) Epidemiology of fractures in England and Wales. Bone 29:517522

2. Engelke K, Gluer CC (2006) Quality and performance measures in bone densitometry: part 1: errors and diagnosis. Osteoporos Int $17: 1283-1292$

3. Burger H, de Laet CE, van Daele PL, Weel AE, Witteman JC, Hofman A, Pols HA (1998) Risk factors for increased bone loss in an elderly population: the Rotterdam Study. Am J Epidemiol 147:871-879

4. Davis JW, Ross PD, Vogel JM, Wasnich RD (1991) Age-related changes in bone mass among Japanese-American men. Bone Miner 15:227-236

5. Hannan MT, Felson DT, Anderson JJ (1992) Bone mineral density in elderly men and women: results from the Framingham osteoporosis study. J Bone Miner Res 7:547-553

6. Jones G, Nguyen T, Sambrook P, Kelly PJ, Eisman JA (1994) Progressive loss of bone in the femoral neck in elderly people: longitudinal findings from the Dubbo osteoporosis epidemiology study. BMJ 309:691-695

7. Center JR, Nguyen TV, Sambrook PN, Eisman JA (1999) Hormonal and biochemical parameters in the determination of osteoporosis in elderly men. J Clin Endocrinol Metab 84:36263635

8. Gennari L, Merlotti D, Martini G, Gonnelli S, Franci B, Campagna S, Lucani B, Dal Canto N, Valenti R, Gennari C, Nuti R (2003) Longitudinal association between sex hormone levels, bone loss, and bone turnover in elderly men. J Clin Endocrinol Metab 88:5327-5333
9. Khosla S, Melton LJ 3rd, Atkinson EJ, O'Fallon WM (2001) Relationship of serum sex steroid levels to longitudinal changes in bone density in young versus elderly men. J Clin Endocrinol Metab 86:3555-3561

10. Khosla S, Melton LJ 3rd, Atkinson EJ, O'Fallon WM, Klee GG, Riggs BL (1998) Relationship of serum sex steroid levels and bone turnover markers with bone mineral density in men and women: a key role for bioavailable estrogen. J Clin Endocrinol Metab 83:2266-2274

11. Szulc P, Munoz F, Claustrat B, Garnero P, Marchand F, Duboeuf F, Delmas PD (2001) Bioavailable estradiol may be an important determinant of osteoporosis in men: the MINOS study. J Clin Endocrinol Metab 86:192-199

12. Van Pottelbergh I, Goemaere S, Kaufman JM (2003) Bioavailable estradiol and an aromatase gene polymorphism are determinants of bone mineral density changes in men over 70 years of age. J Clin Endocrinol Metab 88:3075-3081

13. Fink HA, Ewing SK, Ensrud KE, Barrett-Connor E, Taylor BC, Cauley JA, Orwoll ES (2006) Association of testosterone and estradiol deficiency with osteoporosis and rapid bone loss in older men. J Clin Endocrinol Metab 91:3908-3915

14. Khosla S, Melton LJ 3rd, Robb RA, Camp JJ, Atkinson EJ, Oberg AL, Rouleau PA, Riggs BL (2005) Relationship of volumetric BMD and structural parameters at different skeletal sites to sex steroid levels in men. J Bone Miner Res 20:730-740

15. Szulc P, Uusi-Rasi K, Claustrat B, Marchand F, Beck TJ, Delmas PD (2004) Role of sex steroids in the regulation of bone morphology in men. The MINOS study. Osteoporos Int 15:909917

16. Lauretani F, Bandinelli S, Russo CR, Maggio M, Di Iorio A, Cherubini A, Maggio D, Ceda GP, Valenti G, Guralnik JM, Ferrucci L (2006) Correlates of bone quality in older persons. Bone 39:915-921

17. Bjornerem A, Ahmed LA, Joakimsen RM, Berntsen GK, Fonnebo V, Jorgensen L, Oian P, Seeman E, Straume B (2007) A prospective study of sex steroids, sex hormone-binding globulin, and non-vertebral fractures in women and men: the Tromso Study. Eur J Endocrinol 157:119-125

18. Bjornerem A, Emaus N, Berntsen GK, Joakimsen RM, Fonnebo V, Wilsgaard T, Oian P, Seeman E, Straume B (2007) Circulating sex steroids, sex hormone-binding globulin, and longitudinal changes in forearm bone mineral density in postmenopausal women and men: the tromso study. Calcif Tissue Int 81:65-72

19. Goderie-Plomp HW, van der Klift M, de Ronde W, Hofman A, de Jong FH, Pols HAP (2004) Endogenous sex hormones, sex hormone-binding globulin, and the risk of incident vertebral fractures in elderly men and women: the Rotterdam study. J Clin Endocrinol Metab 89:3261-3269

20. Lee DM, O'Neill TW, Pye SR, Silman AJ, Finn JD, Pendleton N, Tajar A, Bartfai G, Casanueva F, Forti G, Giwercman A, Huhtaniemi IT, Kula K, Punab M, Boonen S, Vanderschueren $\mathrm{D}, \mathrm{Wu}$ FC (2009) The European Male Ageing Study (EMAS): design, methods and recruitment. Int J Androl 32:11-24

21. Augat P, Reeb H, Claes L (1996) Prediction of fracture load at different skeletal sites by geometric properties of the cortical shell. J Bone Miner Res 11:1356-1363

22. Schiessl H, Ferretti J, Tysarczyk-Niemeyer G, Willnecker J (1996) Noninvasive bone strength index as analyzed by peripheral quantitative computed tomography (pQCT). In: Schoenau E (ed) Paediatric osteology: new developments in diagnostics and therapy. Elsevier, Amsterdam, pp 141-146

23. Ward KA, Roberts SA, Adams JE, Mughal MZ (2005) Bone geometry and density in the skeleton of pre-pubertal gymnasts and school children. Bone 36:1012-1018 
24. Ruegsegger P, Kalender W (1993) A phantom for standardization and quality control in peripheral bone measurements by pQCT and DXA. Phys Med Biol 38:1963-1970

25. Labrie F, Bélanger A, Bélanger P, Bérubé R, Martel C, Cusan L, Gomez J, Candas B, Castiel I, Chaussade V, Deloche C, Leclaire J (2006) Androgen glucuronides, instead of testosterone, as the new markers of androgenic activity in women. J Steroid Biochem Mol Biol 99:182-188

26. Labrie F, Bélanger A, Bélanger P, Bérubé R, Martel C, Cusan L, Gomez J, Candas B, Chaussade V, Castiel I, Deloche C, Leclaire J (2007) Metabolism of DHEA in postmenopausal women following percutaneous administration. J Steroid Biochem Mol Biol 103:178-188

27. Wu FC, Tajar A, Pye SR, Silman AJ, Finn JD, O’Neill TW, Bartfai G, Casanueva F, Forti G, Giwercman A, Huhtaniemi IT, Kula K, Punab M, Boonen S, Vanderschueren D, European Male Aging Study Group (2008) Hypothalamic-pituitarytesticular axis disruptions in older men are differentially linked to age and modifiable risk factors. J Clin Endocrinol Metab 93:2737-2745

28. Vermeulen A, Verdonck L, Kaufman JM (1999) A critical evaluation of simple methods for the estimation of free testosterone in serum. J Clin Endocrinol Metab 84:3666-3672

29. Riggs BL, Melton Iii LJ 3rd, Robb RA, Camp JJ, Atkinson EJ, Peterson JM, Rouleau PA, McCollough CH, Bouxsein ML, Khosla S (2004) Population-based study of age and sex differences in bone volumetric density, size, geometry, and structure at different skeletal sites. J Bone Miner Res 19:1945-1954

30. Riggs BL, Melton LJ 3rd, Robb RA, Camp JJ, Atkinson EJ, Oberg AL, Rouleau PA, McCollough $\mathrm{CH}$, Khosla S, Bouxsein ML (2006) Population-based analysis of the relationship of whole bone strength indices and fall-related loads to age- and sexspecific patterns of hip and wrist fractures. J Bone Miner Res 21:315-323

31. Szulc P, Delmas PD (2007) Bone loss in elderly men: increased endosteal bone loss and stable periosteal apposition. The prospective MINOS study. Osteoporos Int 18:495-503

32. Wang X, Kammerer CM, Wheeler VW, Patrick AL, Bunker CH, Zmuda JM (2007) Genetic and environmental determinants of volumetric and areal BMD in multi-generational families of African ancestry: the Tobago Family Health Study. J Bone Miner Res 22:527-536

33. Havill LM, Mahaney MC, Binkley TL, Specker BL (2007) Effects of genes, sex, age, and activity on BMC, bone size, and areal and volumetric BMD. J Bone Miner Res 22:737-746

34. Kaptoge S, Reid DM, Scheidt-Nave C, Poor G, Pols HA, Khaw KT, Felsenberg D, Benevolenskaya LI, Diaz MN, Stepan JJ, Eastell R, Boonen S, Cannata JB, Glueer CC, Crabtree NJ, Kaufman JM, Reeve J (2007) Geographic and other determinants of BMD change in European men and women at the hip and spine. A population-based study from the Network in Europe for Male Osteoporosis (NEMO). Bone 40:662-673

35. Marjanovic E, Ward KA, Adams JE (2009) The impact of accurate positioning on measurements made by peripheral QCT in the distal radius. Osteoporos Int 20:1207-1214

36. Salameh WA, Redor-Goldman MM, Clarke NJ, Reitz RE, Caulfield MP (2010) Validation of a total testosterone assay using high-turbulence liquid chromatography tandem mass spectrometry: total and free testosterone reference ranges. Steroids 75:169-175

37. Bjerner J, Biernat D, Fosså SD, Bjøro T (2009) Reference intervals for serum testosterone, SHBG, LH and FSH in males from the NORIP project. Scand J Clin Lab Invest 69:873-879 